\title{
A SARS-Cov2-negative corona victim
}

\author{
Florian Custodis ${ }^{1}\left[\right.$ [D Konrad Schwarzkopf ${ }^{2} \cdot$ Rosemarie Weimann $^{3} \cdot$ Elmar Spüntrup $^{4} \cdot$ Michael Böhm $^{5} \cdot$ Ulrich Laufs $^{6}$
}

Received: 16 April 2020 / Accepted: 7 May 2020 / Published online: 9 May 2020

(c) Springer-Verlag GmbH Germany, part of Springer Nature 2020

Sirs:

A 48-year-old male was admitted to the specialized COVIDemergency department of a large tertiary hospital on March 27,2020 . The emergency doctor had been dispatched to the home of the patient due to an emergency call. The patient suffered from dyspnea for approximately 7 days. A short episode of an upper airway infection and a contact to a confirmed SARS-Cov2 positive individual was reported. The emergency physician found the patient in acute and severe distress because of dyspnea and thoracic pain. The patient was conscious (Glasgow Coma Scale 15), hypotensive (RR $80 / 60 \mathrm{mmHg}$ ) and tachycardic (120 bpm). Oxygen saturation $\left(\mathrm{SaO}_{2}\right)$ was $70 \%$ despite oxygen insufflation via a nasal canula which prompted immediate intubation on the scene. During transport, repetitive boli of norepinephrine were required to maintain blood pressure. The chest X-ray on admission showed confluent infiltrations in the right and left lung suggestive of a viral pneumonia (Fig. 1).

The laboratory findings on admission are depicted in Fig. 2. As reported for patients with COVID-19, the patient showed low lymphocyte count, elevated neutrophil/

Florian Custodis

fcustodis@klinikum-saarbruecken.de

1 Klinik für Innere Medizin II, Zentrum für Intensiv- und Notfallmedizin (ZIN), Klinikum Saarbrücken, Winterberg 1, 66119 Saarbrücken, Germany

2 Klinik für Anästhesiologie und Intensivmedizin, Zentrum für Intensiv- und Notfallmedizin (ZIN), Klinikum Saarbrücken, Winterberg 1, 66119 Saarbrücken, Germany

3 Institut für Pathologie, Klinikum Saarbrücken, Winterberg 1, 66119 Saarbrücken, Germany

4 Institut für Radiologie, Klinikum Saarbrücken, Winterberg 1, 66119 Saarbrücken, Germany

5 Klinik für Innere Medizin III, Kardiologie, Angiologie und Internistische Intensivmedizin, Universitätsklinikum des Saarlandes, Saarland University, Homburg, Germany

6 Klinik und Poliklinik für Kardiologie, Universitätsklinikum Leipzig, Leipzig, Germany lymphocyte ratio (7.88) and elevated serum concentrations for d-dimers, ferritin and high sensitive troponin (hs-cTn) (495 ng/l). Apart from leukocytosis (19.6/nl), sepsis markers (CRP, Procalcitonin) were in the normal range. An echocardiogram performed by the emergency room staff was reported as "normal". The ECG on admission showed sinus rhythm without ST-elevation (Fig. 3). In view of these findings, acute respiratory failure (ARDS) due to COVID-19 pneumonia and consecutive circulatory failure was proposed as the primary diagnosis.

Within few hours, the patient developed multi-organ failure. After transfer to the ICU, the respiratory $\left(\mathrm{PaO}_{2} / \mathrm{FiO}_{2}\right.$ ratio $74 \mathrm{mmHg}$ ) and hemodynamic situation aggravated rapidly necessitating ventilation in prone position and high dose vasopressor support. Anuric kidney failure, lactate acidosis (pH 7.11; Lactate $6.7 \mathrm{mmol} / \mathrm{l}$; base excess $-13 \mathrm{mmol} / \mathrm{l}$ ) and severe hyperkalemia $(7.4 \mathrm{mmo} / \mathrm{l})$ prompted hemofiltration. A rise of hs-cTn $(3.470 \mathrm{ng} / \mathrm{l})$ corroborated ongoing myocardial damage. Central venous $\mathrm{O}_{2}$-saturation was $73 \%$. Repeated ECG tracings showed no ST-elevations. At this point, potential myocarditis was added to the primary differential diagnosis.

Echocardiography was repeated by a cardiologist revealing a decline in systolic function (LVEF 40\%), a large hypokinesia of the lateral ventricular wall and a floating structure on the mitral valve with moderate mitral valve insufficiency. However, invasive coronary angiography was prohibited due to the clinical situation.

The first swab test for SARS-Cov2 was negative. Due to the patient's history and the clinical presentation, the rapid deterioration in the situation was still considered to be caused by respiratory failure due to COVID-19. A second swab test came in negative for SARS-Cov2 as well as influenza $\mathrm{A}$ and $\mathrm{B}$.

The hemodynamic situation of the patient deteriorated despite maximal catecholamine therapy and the patient died on day 3 after admission. The autopsy showed coronary calcifications and a large type 1 myocardial infarction due to a thrombotic occlusion of the atherosclerotic circumflex coronary artery and rupture of a papillary muscle (Fig. 4). 


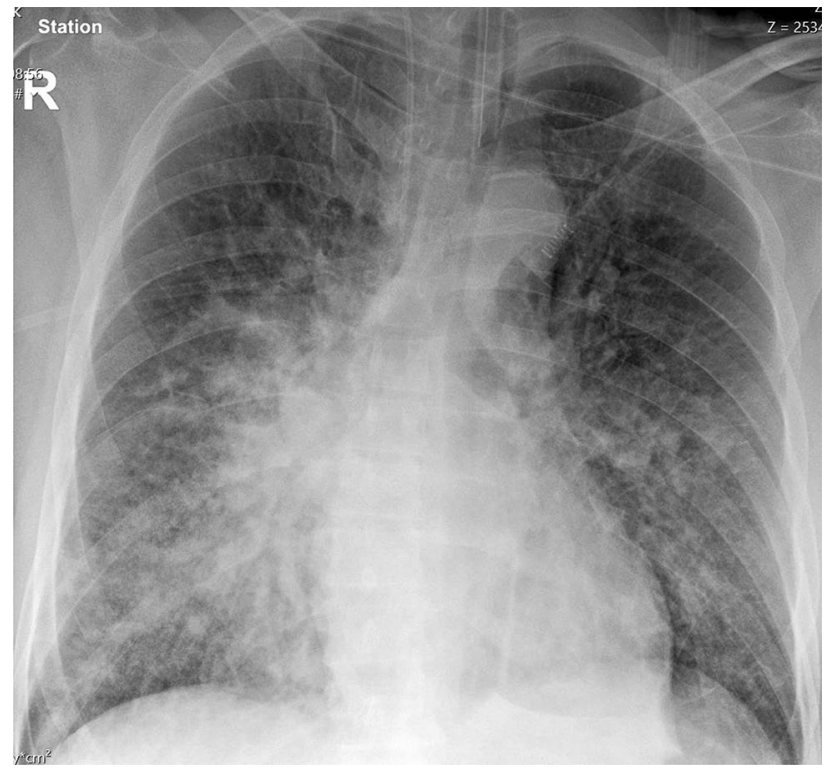

Fig. 1 Chest X-ray on admission

\begin{tabular}{|l|l|l|}
\hline & & Reference range \\
\hline Leukocytes & $19.6 / \mathrm{nl}$ & $(3.7-10.1)$ \\
\hline Thrombocytes & $506 / \mathrm{nl}$ & $(150-361)$ \\
\hline Lymphocytes & $10.8 \%$ & $(18-45 \%)$ \\
\hline Neutrophil/Lymphocyte ratio & 7.88 & \\
\hline D-Dimer & $3.84 \mathrm{mg} / \mathrm{l}$ & $<0.55 \mathrm{mg} / \mathrm{l}$ \\
\hline hs-Troponin & $495 \mathrm{ng} / \mathrm{l}$ & $<14 \mathrm{ng} / \mathrm{l}$ \\
\hline NT-proBNP & $2185 \mathrm{pg} / \mathrm{ml}$ & $<85.8 \mathrm{pg} / \mathrm{ml}$ \\
\hline LDH & $237 \mathrm{U} / \mathrm{l}$ & $<225 \mathrm{U} / \mathrm{l}$ \\
\hline Creatinin & $1.7 \mathrm{mg} / \mathrm{dl}$ & $<1.2 \mathrm{mg} / \mathrm{dl}$ \\
\hline GFR & $47 \mathrm{ml} / \mathrm{min}$ & $>60 \mathrm{ml} / \mathrm{min}$ \\
\hline Ferritin & $424 \mathrm{\mu g} / \mathrm{l}$ & $27-365 \mu \mathrm{\mu g} / \mathrm{l}$ \\
\hline Potassium & $4.4 \mathrm{mmol} / \mathrm{l}$ & $(3.5-5.3 \mathrm{mmol} / \mathrm{l})$ \\
\hline Sodium & $137 \mathrm{mmol} / \mathrm{l}$ & $(135-148 \mathrm{mmo} / \mathrm{l})$ \\
\hline
\end{tabular}

Fig. 2 Laboratory results on admission
The 48-year-old patient without known significant comorbidities died from a type 1 myocardial infarction of the circumflex artery that was complicated by ischemic mitral valve insufficiency due to rupture of a papillary muscle. Due to the massive efforts to avoid infections of hospital patients and staff with SARS-Cov2 and the subsequent shifts in the organization of emergency care and the attention of the medical staff involved, the pathogenesis of the patient was only recognized post-mortem. Despite the very important measures to contain SARSCov2, it remains key to follow established clinical pathways. Importantly, cardiologists are important for the full assessment of hemodynamically compromised patients.

The novel coronavirus SARS-Cov2 and its clinical sequelae (so called coronavirus disease-COVID-19) has a wide spectrum of symptoms from asymptomatic causes to flu-like symptoms and finally pneumonia with acute respiratory distress syndrome [1]. Due to the clinical cause of COVID-19, the disease shares many of the initial symptoms with life-threatening cardiovascular diseases such as heart failure, myocardial ischemia and myocardial infarction and the virus might also involve the myocardium itself [2]. In patients with COVID-19, myocardial injury often develops $[3,4]$ and is associated with poor outcomes [5] as cardiovascular comorbidity load is high [6]. Furthermore, viral infections and pneumonia are associated with an increased risk for subsequent cardiovascular disease and myocardial infarction [7].

This case is an unfortunate example of a SARS-Cov2negative corona victim, in whom all attention was placed on the possibility of COVID-19 infection. This case also highlights the need for emergency strategies to identify and treat life-threatening cardiovascular disease mimicking COVID19 symptoms or coexisting in the presence of COVID-19. Physicians should pay great attention to cardiac symptoms and not lose focus on life-threatening cardiovascular disease, though it can sometimes hardly be distinguished from a COVID-19 infection, one of the major challenges nowadays. 

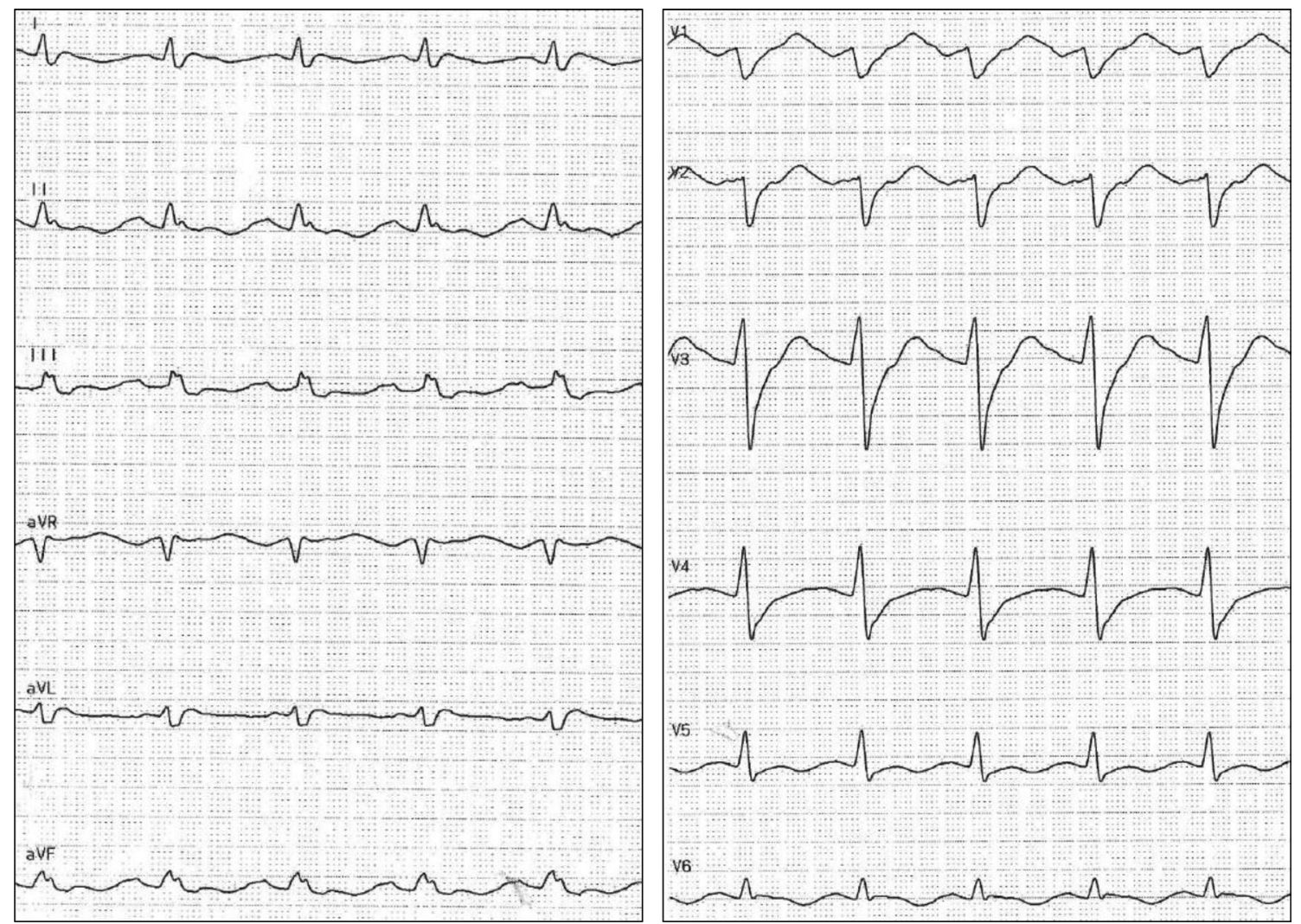

Fig. 3 Electrocardiogram on admission
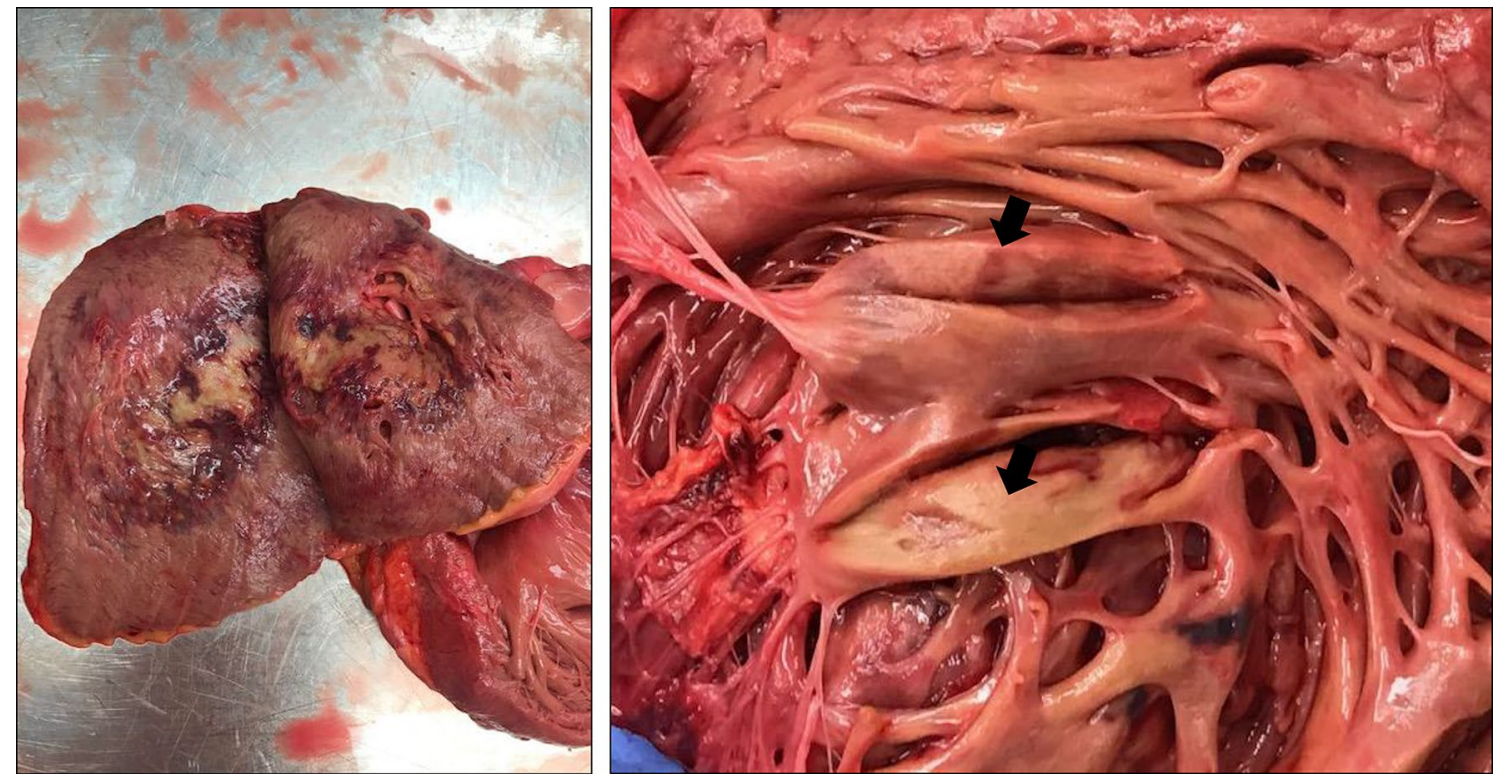

Fig. 4 Autopsy revealed acute and extended myocardial ischemia of the lateral wall of the left ventricle (left) and rupture of the ischemic papillary muscle. Arrows mark "tiger sign" of the papillary muscle indicating ischemic damage 


\section{Compliance with ethical standards}

Conflict of interest On behalf of all authors, the corresponding author states that there is no conflict of interest.

\section{References}

1. Wu Z, McGoogan JM (2020) Characteristics of and important lessons from the Coronavirus Disease 2019 (COVID-19) outbreak in China: summary of a report of 72,314 cases from the Chinese Center for disease control and prevention. JAMA. https://doi. org/10.1001/jama.2020.2648

2. Zeng JH, Liu YX, Yuan J, Wang FX, Wu WB, Li JX, Wang LF, Gao H, Wang Y, Dong CF, Li YJ, Xie XJ, Feng C, Liu L (2020) First case of COVID-19 complicated with fulminant myocarditis: a case report and insights. Infection. https://doi.org/10.1007/s1501 0-020-01424-5

3. Ruan Q, Yang K, Wang W, Jiang L, Song J (2020) Clinical predictors of mortality due to COVID-19 based on an analysis of data of 150 patients from Wuhan, China. Intensive Care Med. https:// doi.org/10.1007/s00134-020-05991-x
4. Huang C, Wang Y, Li X, Ren L, Zhao J, Hu Y, Zhang L, Fan G, Xu J, Gu X, Cheng Z, Yu T, Xia J, Wei Y, Wu W, Xie X, Yin W, Li H, Liu M, Xiao Y, Gao H, Guo L, Xie J, Wang G, Jiang R, Gao Z, Jin Q, Wang J, Cao B (2020) Clinical features of patients infected with 2019 novel coronavirus in Wuhan, China. Lancet 395:497-506

5. Shi S, Qin M, Shen B, Cai Y, Liu T, Yang F, Gong W, Liu X, Liang J, Zhao Q, Huang H, Yang B, Huang C (2020) Association of cardiac injury with mortality in hospitalized patients with COVID-19 in Wuhan, China. JAMA Cardiol. https://doi. org/10.1001/jamacardio.2020.0950

6. Li B, Yang J, Zhao F, Zhi L, Wang X, Liu L, Bi Z, Zhao Y (2020) Prevalence and impact of cardiovascular metabolic diseases on COVID-19 in China. Clin Res Cardiol. https://doi.org/10.1007/ s00392-020-01626-9

7. Corrales-Medina VF, Alvarez KN, Weissfeld LA, Angus DC, Chirinos JA, Chang CC, Newman A, Loehr L, Folsom AR, Elkind MS, Lyles MF, Kronmal RA, Yende S (2015) Association between hospitalization for pneumonia and subsequent risk of cardiovascular disease. JAMA 313:264-274 